\title{
Commentary: UN high level meeting on non-communicable diseases: an opportunity for whom?
}

\author{
David Stuckler university lecturer in sociology ${ }^{1}$, Sanjay Basu physician ${ }^{2}$, Martin McKee professor \\ of European public health ${ }^{3}$
}

${ }^{1}$ Department of Sociology, Cambridge University, Cambridge CB2 3RQ, UK ; ${ }^{2}$ Department of Medicine, University of California San Francisco, San Francisco CA, USA; ${ }^{3}$ London School of Hygiene and Tropical Medicine, London, UK

In September, world leaders will meet at the United Nations in New York to discuss non-communicable diseases. ${ }^{1}$ A decade ago, at a similar meeting on HIV/AIDS, they created the Global Fund for HIV/AIDS, Tuberculosis and Malaria-a revolutionary new global health funding mechanism. ${ }^{2}$

The September meeting will focus on four leading conditions - heart disease, cancer, diabetes, and respiratory disease - that together cause more than half of all deaths in low and middle income countries. ${ }^{3}$ Without action, the number of premature deaths $($ age $<60)$ caused by non-communicable diseases is expected to rise from 3.8 million each year to 5.1 million in poor countries by 2030, trapping a generation of families in cycles of poverty and disease..$^{4-6}$ As Thomas Frieden, director of the US Centers for Disease Control and Prevention, recently stated, developing countries must immediately tackle the rapid rise of non-communicable diseases because they will "kill four times as many people by 2020 as infectious diseases."7

Hopes are high that the UN meeting will mark a turning point and avoid the belated response that hampered HIV strategies. Progress on HIV required not only technical discussions about which drugs work and how to make them cost effective; it also needed to tackle the broader ethical, social, and political dimensions of the HIV pandemic. ${ }^{8}$

Throughout the process, the imperative to act was presented as one of social justice. It emphasised that HIV was a manifestation of inequalities in power and resources. Efforts by drug companies to protect long term patents on antiretroviral drugs were met by activists fighting for access to treatment and declaring that human lives in poor countries were just as valuable as those in rich ones.

\section{Misconception and neglect}

Non-communicable diseases, by contrast, remain neglected despite their social parallels to HIV. ${ }^{9-11}$ As with HIV, discussions are plagued by misconceptions. Although they have been thought of as diseases of the wealthy, this is simply incorrect (box).

Another common fallacy is that non-communicable diseases stem from a moral failure - that weakness of will leads to obesity or sedentary lifestyles. But people in many parts of the world face major barriers to making healthy choices and face powerful pressures to adopt unhealthy ones. ${ }^{15}$

Pervasive fallacies have led to serious under-budgeting for non-communicable diseases (box). As the health minister of Uganda put it, "We know what to do [but] we have no budget."15

The paradoxes are obvious to observers in developing countries. Guyana's health minister, Leslie Ramsammy, pointed to the fact that the millennium development goals did not include non-communicable diseases even though they account for $60 \%$ of global deaths. "Most of the morbidity and mortality caused by the chronic diseases are preventable. [This is] a serious omission," he said. ${ }^{15}$

Because non-communicable diseases are not part of the goals, development agencies fail to prioritise them; health ministers in turn do not seek support for prevention and control because of the lack of available funding. Little research can be done on how to prevent and treat these conditions, and this allows cynics to argue there is weak evidence for intervention-a Catch 22 situation is created.

Yet proved and cost effective interventions do exist (box). ${ }^{19}$ For example, the World Bank says tobacco and alcohol taxes, smoking bans to reduce deaths, and treatment of acute myocardial infarction with aspirin and $\beta$ blockers are among the most cost effective measures for disease control available in low income countries. ${ }^{20}$

\section{Vested interests}

So why has there been no clear response to non-communicable diseases? One crucial difference from HIV is that there has been 


\section{Epidemiology of non-communicable diseases \\ - The common non-communicable diseases increasingly affect the poorest in low and middle income countries, just as in high income nations ${ }^{312}$ \\ - Women aged 15-49 in sub-Saharan Africa are four times more likely to die or experience disability from a non-communicable disease than women in high income countries ${ }^{13}$ \\ - High blood pressure is the second leading risk factor for death in low income countries (behind child underweight), and high blood glucose is the fifth ${ }^{14}$}

\section{Funding gap \\ - One survey of health ministers worldwide found that only about a third had even a single budget line for non-communicable diseases ${ }^{16}$ \\ - Overall, less than $3 \%$ of global health aid has been designated for non-communicable diseases ${ }^{17}$ \\ - WHO-which has provided the strongest support to NCDs among global institutions-allocates less than $10 \%$ of its budget to these diseases ${ }^{18}$}

\section{Evidence based action}

- Tobacco and alcohol tax increases have been shown to reduce consumption as well as raise revenue for governments ${ }^{21-23}$

- A meta-analysis of alcohol tax studies estimated that a doubling of the price of alcohol beverages would reduce alcohol related mortality by $35 \%$, traffic crash deaths by $11 \%$, sexually transmitted diseases by $6 \%$, violence by $2 \%$, and crime by $1.4 \%{ }^{24}$

- Salt reduction reduces blood pressure and risks of cardiovascular disease. Regulating salt intake could save billions in healthcare costs annually ${ }^{25}$

no strong base of advocates to tackle the root social causes of illness. Advocacy on non-communicable diseases has been described by young people as "dull" and "uninspiring," lacking an emphasis on social justice or inequality and missing a sense of outrage and urgency against continued inaction.

As a result, much of the agenda is being written by powerful vested interests. Margaret Chan, director general of WHO, stated that "Today, many of the threats to health that contribute to NCDs come from corporations that are big, rich and powerful, driven by commercial interests, and far less friendly to health. Today, more than half of the world's population lives in an urban setting. Slums need corner food stores that sell fresh produce, not just packaged junk with a cheap price and a long shelf-life." 26

At a preparatory meeting in New York representatives of the United States, Europe, and key Western allies, blocked consensus on action on non-communicable diseases after lobbying from the alcohol, food, tobacco, and drug industries. Negotiations have now stalled. When asked why Michelle Obama's successful childhood obesity programmes in the US should not be modelled in developing countries, a US official responded that they might harm American exports.

The current draft of the declaration on non-communicable diseases has no time bound commitments; does not allocate resources to prevent and control these diseases; and does not include language focusing on the most cost effective fiscal and regulatory interventions.

The NCD Alliance, a leading non-governmental advocacy group, highlights the "unwillingness" of donor countries to call for increased resources for non-communicable diseases and for "the need for evidence-based fiscal policies such as increased taxation on tobacco."

Food companies have hired US President Obama's former communications director, Anita Dunn, to lead lobbying efforts on food regulations; these industries look to low and middle income countries as their greatest growth markets. ${ }^{27}$

There is also evidence that food companies have worked through US diplomats to secure a more favourable economic and legal environment in developing countries. McDonald's sought to delay the implementation of new US free trade legislation until El Salvador appointed new judges to resolve an ongoing court dispute. ${ }^{28}$

Should the industries that profit from unhealthy products be viewed as trusted partners and have a seat at the table during public health negotiations? At recent UN civil society hearings - the main opportunity for advocates to shape the final UN political declaration-representatives from food (including the International Food and Beverage Alliance) and alcohol industries (including Anheuser-Busch, SABMiller, and the Global Alcohol Producers group) were among the main representatives of civil society. Alcohol industry representatives said at a preparatory meeting: "We will do anything as long as it is voluntary."

Corporate influence takes many, often subtle and indirect forms. Philip Morris's latest campaign, "Project Sunrise," explicitly aims to "weaken tobacco control by working with it," funding front groups and exploiting differences of opinion within the tobacco control movement to "create schisms-force them to fight among themselves." ${ }^{29}$

Where collaboration does not work, direct threats may be used. After WHO released its report on diet, physical activity, and health in 2003, which recommended reduced sugar intake, the sugar industry threatened that it would lobby the US to cut off its financial support to WHO. Three of Washington's largest lobbying firms now work for the food industry. ${ }^{30}$ Vested interests also pose a problem for the non-governmental organisations that are most actively engaged in the UN civil society hearings. Many receive a considerable proportion of their funding from 
drug companies or food companies, potentially compromising their ability to argue for greater use of generic drugs or taxation and regulatory interventions. ${ }^{31}$

Policy debates may also be shaped by decisions on what is prioritised and what is not in global health. For example, the Bill and Melinda Gates Foundation, which funds more than $\$ 3.5 \mathrm{bn}$ of global health research each year, offers less than 3\% of its funding for research into non-communicable diseases, ${ }^{32} 33$ while holding large stocks in food and drink companies (owning $10 \%$ of global Coca-Cola stock, for example). ${ }^{31}$

Like the HIV meeting, the UN high level meeting on non-communicable diseases is a battleground, pitting public interests against powerful private ones. But unlike the HIV activism of the past, the voices of people affected by non-communicable diseases are mostly quiet. Whether the meeting encourages the emergence of a global social movement for change will shape the future of our health for years to come.

Competing interests: All authors have completed the ICJME unified disclosure form at www.icmje.org/coi_disclosure.pdf (available on request from the corresponding author) and declare no support from any organisation for the submitted work; no financial relationships with any organisation that might have an interest in the submitted work in the previous three years; and no other relationships or activities that could appear to have influenced the submitted work.

Provenance and peer review: Commissioned; not externally peer reviewed.

United Nations. Prevention and control of non-communicable disease. United Nations, 2010.

2 Ooms G, Stuckler D, Basu S, McKee M. Financing the millennium development goals for health and beyond. Global Health 2010;6:17.

3 WHO. Mortality and burden of disease estimates for WHO member states in 2004. WHO, 2009.

4 Beaglehole R, Bonita R, Horton R, Adams C, Alleyne G, Asaria P, et al. Priority actions for the non-communicable disease crisis. Lancet 2011;377:1438-47.

5 Beaglehole R, Bonita R, Alleyne G, Horton R, Li L, Lincoln P, et al. UN high-level meeting on non-communicable disease: addressing four questions. Lancet (forthcoming).

6 Beaglehole R, Ebrahim S, Reddy S, Voute J, Leeder S. Prevention of chronic diseases: a call to action. Lancet 2007:370:2152-7.

7 Pokharel K. India's efforts on TB, tobacco control lauded. Wall Street Journal 2011. http: //blogs.wsj.com/indiarealtime/2011/08/09/india\%E2\%80\%99s-efforts-on-tb-tobacco-controllauded/.

8 Geneau R, Stuckler D, Stachenko S, McKee M, Ebrahim S, Basu S, et al. Raising the priority of preventing chronic disease: A political process. Lancet 2011:376:1689-98.

9 Delamothe T. Aid agencies neglect non-communicable diseases, international health organisations warn. BMJ 2009;338:b2102.
10 Barnes P. Chronic obstructive pulmonary disease: a growing but neglected global epidemic. PLoS Med 2007:4:e112.

11 Horton R. The neglected epidemic of chronic disease. Lancet 2005;366:1514

12 WHO. Global health risks: mortality and burden of disease attributable to selected major risks. WHO, 2009.

13 Alwan A, Galea G, Stuckler D. Development at risk: addressing noncommunicable diseases at the United Nations high-level meeting. Bull World Health Organ 2011;89:546.

14 Narayan K, Ali MK, Koplan JP. Global noncommunicable diseases-where worlds meet. N Engl J Med 2010;363:1196-8.

15 Stuckler D, Siegel K. Sick societies: responding to the global challenge of chronic disease. Oxford University Press, 2011.

16 Yach D, Hawkes C. Towards a WHO long-term strategy for prevention and control of leading chronic diseases. WHO, 2004.

17 Nugent R, Feigl A. Scarce donor funding for non-communicable diseases: Will it contribute to a health crisis? Center for Global Development, 2010.

18 Stuckler D, Robinson HR, McKee M, King L. World Health Organization budget and burden of disease: a comparative analysis. Lancet 2008;372:1563-9.

19 Capewell S, O'Flaherty M. Rapid mortality falls after risk-factor changes in populations. Lancet (forthcoming).

20 Jamison D, Breman JG, Measham AR, Alleyne G, Claeson M, Evans DB, et al. Disease control priorities in developing countries. World Bank, 2006.

21 Kostova D, Ross H, Belcher E, Markowitz S. Prices and cigarette demand: evidence from youth tobacco use in developing countries. NBER working paper No 15781. National Bureau of Economic Research, 2010.

22 Zhang B, Cohen J, Ferrence R, Rehm J. The impact of tobacco tax cuts on smoking initiation among Canadian young adults. Am J Prev Med 2006:30:474-9.

23 Wagenaar A, Maldonado-Molina MM, Wagenaar BH. Effects of alcohol tax increases on alcohol-related disease mortality in Alaska: time-series analyses from 1976 to 2004. Am $J$ Pub Health 2009;99:1464-70.

24 Wagenaar A, Tobler AL, Komro KA. Effects of alcohol tax and price policies on morbidity and mortality: a systematic review. Am J Public Health 2010;100:2270-8.

25 Bibbins-Domingo K, Chertow GM, Coxson PG, Moran A, Lightwood JM, Pletcher MJ, et al. Projected effect of dietary salt reductions on future cardiovascular disease. $N$ Engl $J$ Med 2010;362:590-9.

26 Labonte R, Mohindra KS, Lencucha R. Framing international trade and chronic disease. Global Health 2011;7:21.

27 Layton L, Eggen D. Industries lobby against voluntary nutrition guidelines for food marketed to kids. Washington Post 2011 Jul 9. www.washingtonpost.com/politics/industries-lobbyagainst-voluntary-nutrition-guidelines-for-food-marketed-to-kids/2011/07/08/gIQAZSZu5H story.html.

28 Boseley S. WikiLeaks cables: McDonald's used US to put pressure on El Salvador. Guardian 2010 Dec 21. www.guardian.co.uk/business/2010/dec/21/wikileaks-cablesmcdonalds-us-el-salvador.

29 McDaniel P, Smith EA, Malone RE. Philip Morris's Project Sunrise: weakening tobacco control by working with it. Tobacco Control 2006:15:215-23.

30 Freudenberg N. Who advances the food industry's political agenda? Corporations and Health Watch 2011 Jul 27. www. corporationsandhealth.org/news/201/62/Who-Advancesthe-Food-Industry-s-Political-Agenda/d,Article.

31 Stuckler D, Basu S, McKee M. Global health philanthropy and institutional relationships: How should conflicts of interest be addressed? PLoS Med 2011;8:e1001020.

32 McNeil D Gates Foundation's influence criticized. New York Times 2008 Feb 16 . www. nytimes.com/2008/02/16/science/16malaria.html? $r=3 \&$ ref=health\&oref=slogin\&oref=login.

33 McCoy D, Kembhavi G, Patel J, Luintel A. The Bill \& Melinda Gates Foundation's grant-making programme for global health. Lancet 2009;373:1645-53.

\section{Cite this as: BMJ 2011:343:d5336}

(C) BMJ Publishing Group Ltd 2011 